\title{
FINITE ELEMENT ANALYSIS OF HEAT TRANSFER IN MULTI-LAYER COOKING POTS WITH EMPHASIS ON LAYER NUMBER
}

\author{
Mohammadreza Sedighi ${ }^{*}$ and Behnam Nilforooshan Dardashti ${ }^{2}$ \\ ${ }^{1}$ Young Researchers Club, Islamic Azad University Bueenzahra Branch, \\ Bueenzahra, Iran; Phone: +989357816710 \\ ${ }^{2}$ Department of Mechanical Engineering, \\ Islamic Azad University Bueenzahra Branch, Bueenzahra, Iran \\ *e-mail: mr_sedighi@iaunour.ac.ir
}

\begin{abstract}
The goal of this research was to numerically assess the dependence of cookware performance on the number of layers and materials as defined by the uniform surface temperature and average temperature on the cooking surface. The objectives of this research were: to quantify the temperature distribution in items of cookware based on variation of the number of layers and thermal properties by using a finite element model of heat transfer in cookware. 625 types of composite cookware were compared in terms of thermal performance. The results show that a higher thermal conductivity material yields a more uniform surface temperature profile than a lower thermal conductivity material. In addition, cookware with a two-ply base provides a more uniform temperature profile and heat transfer compared with one, three and four layers. Low conduction materials used in a thin second layer with conductive metals as a first layer reduce the temperature differences up to $180 \mathrm{~K}$. Moreover, this combination with high conduction metals used in a thick first layer provides a high mean temperature on the non-heated surface.
\end{abstract}

Keywords: Cookware; conduction; finite element method; multi-layer plate.

\section{INTRODUCTION}

An ideal cookware should be designed to get the maximum heat from the burner to increase its efficiency and economize on energy. Besides, it should meet the majority of consumer demands including being lightweight and durable, keeping the contents hot for a relatively long time, avoiding hot spots on the cooking surface and having a nonstick surface. It also has to guarantee the health of the consumers, and so must not react with the contents. We can satisfy a wide variety of demands including superior mechanical, chemical and thermal properties by using multiple materials together $[1,2]$. One way of reducing house energy consumption is to design heating facilities, which are more economical in their use of energy [3]. Generally, a multi-layer structure and the material properties of the layers have a high impact on improving the thermal behavior of cookware, and can optimize the energy consumption. The energy is obtained mainly from burning gas and electrical resistivity. The heat is not uniformly spread over the pan in either method. Using a multi-layer plate provides regular temperature distribution on the top when the bottom is heated unevenly [4-6]. There are a few academic papers that have used experimental or numerical methods to study cookware performance. A computer code, finite difference, was developed to study a 
single pan stove [7]. Ashman, Junus [8] used an experimental method to study the behavior of efficiency and pollution dissipation from the burning head. Sabilov, Farkas [9] used a finite element method to simulate conduction heat transfer through the dish wall. They also studied the effect of conductivity on cooking quality. An analytical model was used by Jugjai and Rungsimuntuchart [10] to simulate convection heat transfer from the burning head to the dish. They found the highest efficiency by using a swirling central flame. Lucky and Hossain [11] conducted an experimental research on Bangladeshi cookstoves. They found that a pan is more efficient than a pot. Karzar Jeddi, Kazemzadeh Hannani [12] used the finite element method to model heat transfer through burners to the pan. Ayata [13] used the finite element, ANSYS program, to model the temperature distributions in the copper and aluminum layered base of a chromium nickel saucepan. Sedighi and Dardashti [14] studied the dependence of heat transfer on materials. In the current work, a numerical simulation of the system has been carried out using the finite element method to study the dependence of heat transfer on the thicknesses and number of layers, the materials and geometric properties. The authors believe that the thermal analysis of multi-metal cookware with one to four layers and different materials is applied here for the first time. The intention of this investigation is to try to bridge the information gap.

\section{MATERIALS AND METHODS}

The annular part of the circular surface of the bottom side of a plate illustrated as $r$ in Figure 1, was constrained to a fixed temperature of $773(\mathrm{~K})$ to model an irregular heat source. There is a geometrical symmetry so the system can be modeled by a rectangular plane with the length of the pan radius and a thin and long rectangle as the wall of the pan. Because of the symmetry, the temperature gradients at the center of the plate along the y-axis have zero value. Hence there is no heat flux at the center of the plate along the y-axis. The side of the pan has convection heat transfer with air at ambient temperature. The thickness of the plate is $10 \mathrm{~mm}$.

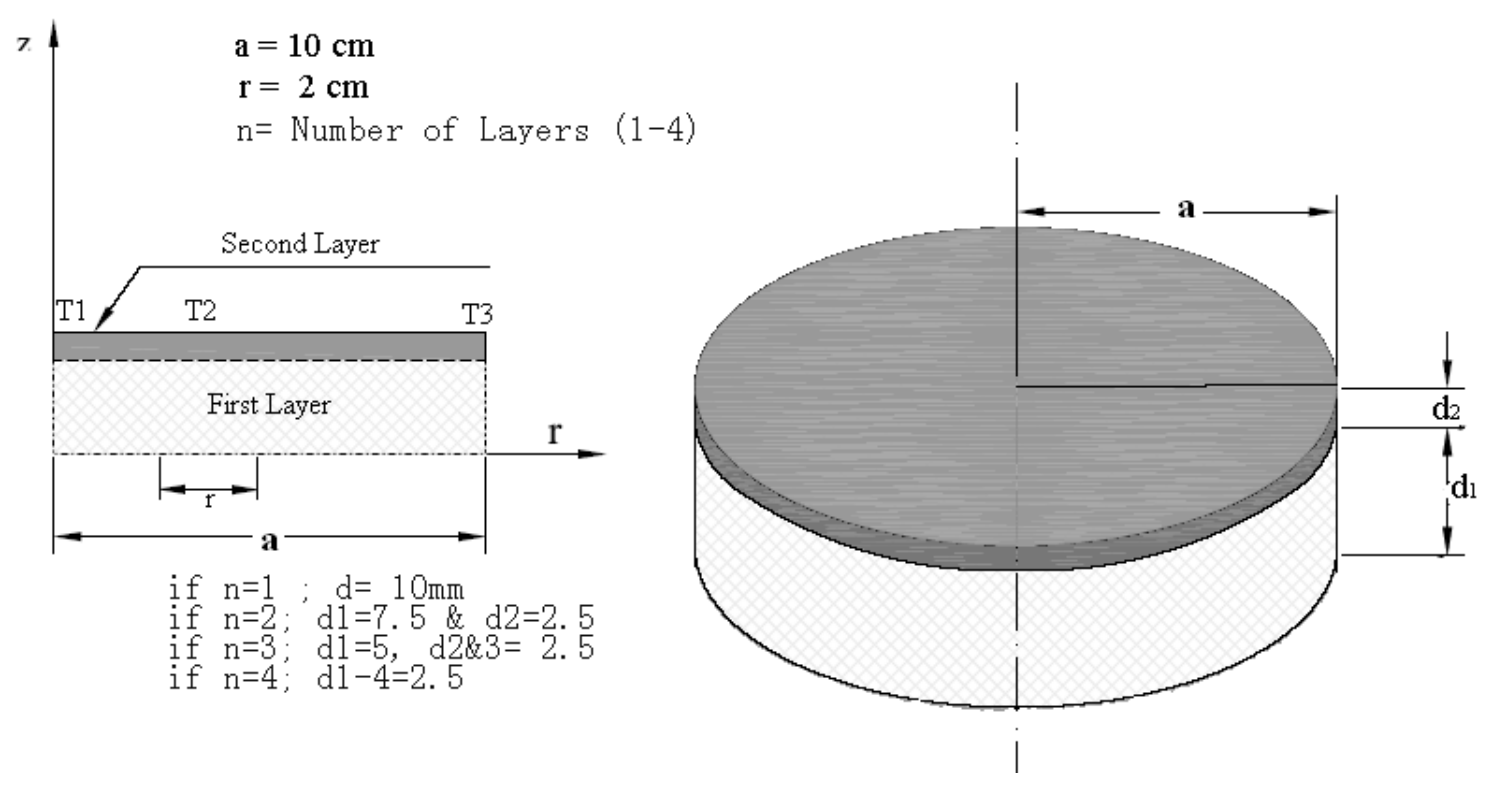

Figure 1.2D and 3D schematic of section of a circular bi-layer plate. 
The analysis has been extended to four, three and two layers as well as a single layer. In four layers, all layers have the same thickness of $2.5 \mathrm{~mm}$. In three layers, one layer is $5 \mathrm{~mm}$ and the other two are $2.5 \mathrm{~mm}$. For two layers, the thicknesses are 7.5 and $2 \mathrm{~mm}$. The ambient temperature and the coefficient of heat transfer have been assumed as $293 \mathrm{~K}$ and $17 \mathrm{~W} / \mathrm{m}^{2} . \mathrm{K}$, respectively. In addition, it is also assumed that the pan is filled with water at boiling temperature, and the coefficient of heat transfer between the pan and the water is $50 \mathrm{~W} / \mathrm{m}^{2} . \mathrm{K}$. Copper $(\mathrm{Cu})$, aluminum $(\mathrm{Al})$, chromium nickel $(\mathrm{CrNi})$, titanium (Ti) and stainless steel (SSt) have been applied in each layer. A loop was defined to change the five materials through the four layers. Overall, 625 models were analyzed. The properties of the applied metals are according to Bergman and Incropera [15].

\section{Numerical Method}

In the finite element method, a given computational domain is subdivided as a collection of a number of finite elements, subdomains of variable size and shape, which are interconnected in a discrete number of nodes. The solution of the partial differential equation is approximated in each element by a low-order polynomial in such a way that it is defined uniquely in terms of the solution at the nodes. The global solution can then be written as series of low-order piecewise polynomials with the coefficients of the series equal to the approximate solution at the nodes [16]. Solution of the twodimensional heat analysis finite element method is governed by [17]:

$$
\begin{gathered}
\{g\}=\left\{\begin{array}{l}
\frac{\partial T}{\partial x} \\
\frac{\partial T}{\partial y}
\end{array}\right\}=\left[\begin{array}{l}
\frac{\partial N_{i}}{\partial x} \frac{\partial N_{j}}{\partial x} \frac{\partial N_{m}}{\partial x} \\
\frac{\partial N_{i}}{\partial y} \frac{\partial N_{j}}{\partial y} \frac{\partial N_{m}}{\partial y}
\end{array}\right]\left\{\begin{array}{l}
t_{i} \\
t_{j} \\
t_{m}
\end{array}\right\} \\
{[B]=\frac{\partial}{\partial x}[N]=\frac{1}{|x|}\left[\begin{array}{l}
\beta_{i} \beta_{j} \beta_{m} \\
\gamma_{i} \gamma_{j} \gamma_{m}
\end{array}\right]}
\end{gathered}
$$

where analogous to a strain matrix $\{\mathrm{g}\}=[\mathrm{B}]\{\mathrm{t}\}$ and $[\mathrm{B}]$ is a derivative of $[\mathrm{N}]$. The heat flux and temperature gradient are written as:

$$
\left\{\begin{array}{l}
q_{x} \\
q_{y}
\end{array}\right\}=-\left[\begin{array}{cc}
\mathrm{K}_{\mathrm{xx}} & 0 \\
0 & \mathrm{~K}_{\mathrm{yy}}
\end{array}\right]\{g\}=-[D]\{g\}
$$

The first term of Equation (4) is the conduction portion and the second term is the convection portion of the total stiffness matrix.

$$
[k]=\iiint_{V}[B]^{T}[D][B] d V+\iint_{S} h[N]^{T}[N] d S
$$


where the heat source is constant, we have:

$$
\begin{gathered}
\left\{f_{Q}\right\}=Q \iiint_{V}[V]^{T} d V=\frac{Q V}{3}\left\{\begin{array}{l}
1 \\
1 \\
1
\end{array}\right\} \\
\{f\}=[k]\{t\}
\end{gathered}
$$

The stiffness matrix is a general term for a matrix of known coefficients being multiplied by unknown degrees of freedom, i.e., temperature, etc. Thus, the element conduction matrix is often referred to as the stiffness matrix.

$$
\{F\}=[K]\{t\}
$$

Heat flux boundary conditions are already accounted for in the derivation. We just substitute into the above equation and solve for the nodal temperature and element temperature gradient [17].

\section{RESULTS AND DISCUSSION}

In this part, copper, aluminum, chromium nickel, titanium and stainless steel were used in each layer to determine the behavior of the two parameters of mean temperature (Tmean) and temperature differences (DT=Tmax-Tmin) on the cooking surface of the plate. Figure 2 illustrates the mean temperature on the cooking surface of the cookware. The maximum point occurs when all four layers are copper. This means that the copper single-layer plate provides the highest mean temperature. As shown in Figure 2, the mean temperature on the cooking surface increases with the use of conductive metals. Hence aluminum, compared with titanium, stainless steel and chromium nickel, provides the highest mean temperature.

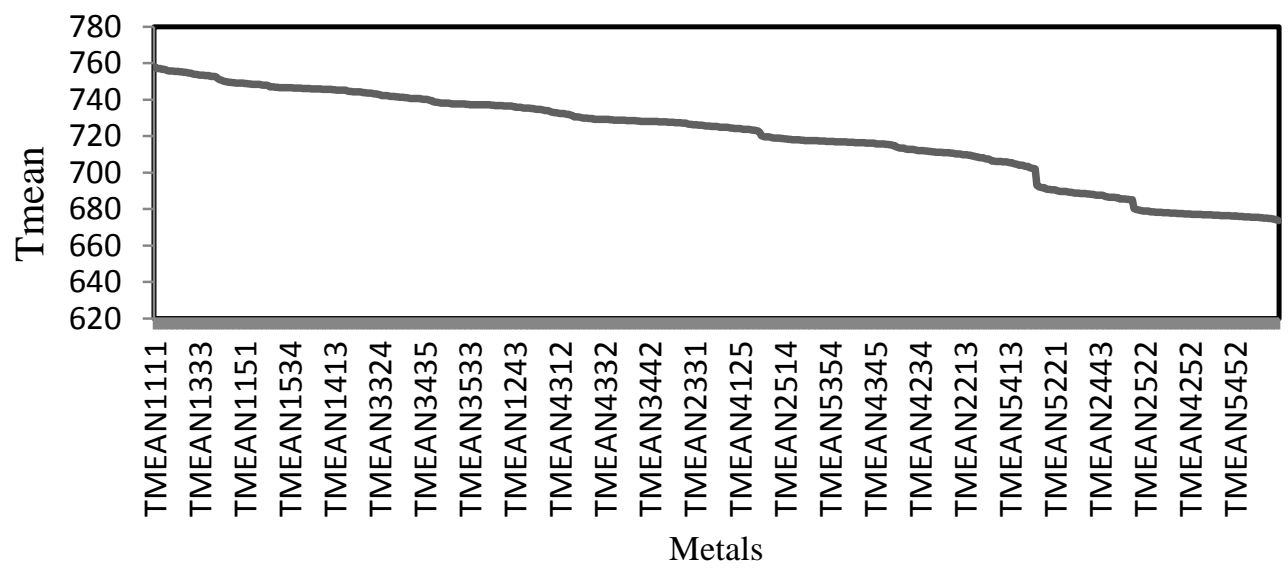

Figure 2. Mean temperature on cooking surfaces of multi-metal plates.

*The order of numbers indicates the materials of the first to fourth layers. The numbers indicate the metals as follows:

$$
1=\mathrm{Cu} \quad 3=\mathrm{ASt} \quad 4=\mathrm{CrNi} \quad 5=\mathrm{Ti}
$$


The plates whose first layers are conductive metals such as copper and aluminum show clearly different behavior from the plates whose first layers are lowconduction metals. The mean temperatures in plates whose first layer is a lowconduction metal are approximately the same. The maximum temperatures of the stainless steel, chromium nickel and titanium are $737.3 \mathrm{~K}, 735.7 \mathrm{~K}$ and $735.15 \mathrm{~K}$ respectively. The difference of the maximum and minimum temperatures on the top surface of the multi-metal plates is illustrated in Figure 3. The minimum temperature difference occurs with $\mathrm{P}_{\mathrm{Cu} / \mathrm{CrNi}}\left(\mathrm{P}_{1114}\right.$ or $\left.\mathrm{P}_{\mathrm{Cu} / \mathrm{Cu} / \mathrm{Cu} / \mathrm{CrNi}}\right)$, and is as low as $35.2 \mathrm{~K}$. This means that the bi-layer plate with $\mathrm{Cu}$ and $\mathrm{CrNi}$ layers with thicknesses of $7.5 \mathrm{~mm}$ and $2.5 \mathrm{~mm}$ respectively provides the most uniform temperature distribution on the cooking surface. Plates whose first layers are conductive metals such as copper and aluminum have lower temperature differences than plates whose first layers are low-conduction metals. The maximum DT was provided by $\mathrm{P}_{\mathrm{CrNi} / \mathrm{Ti}}$ at $216 \mathrm{~K}$.

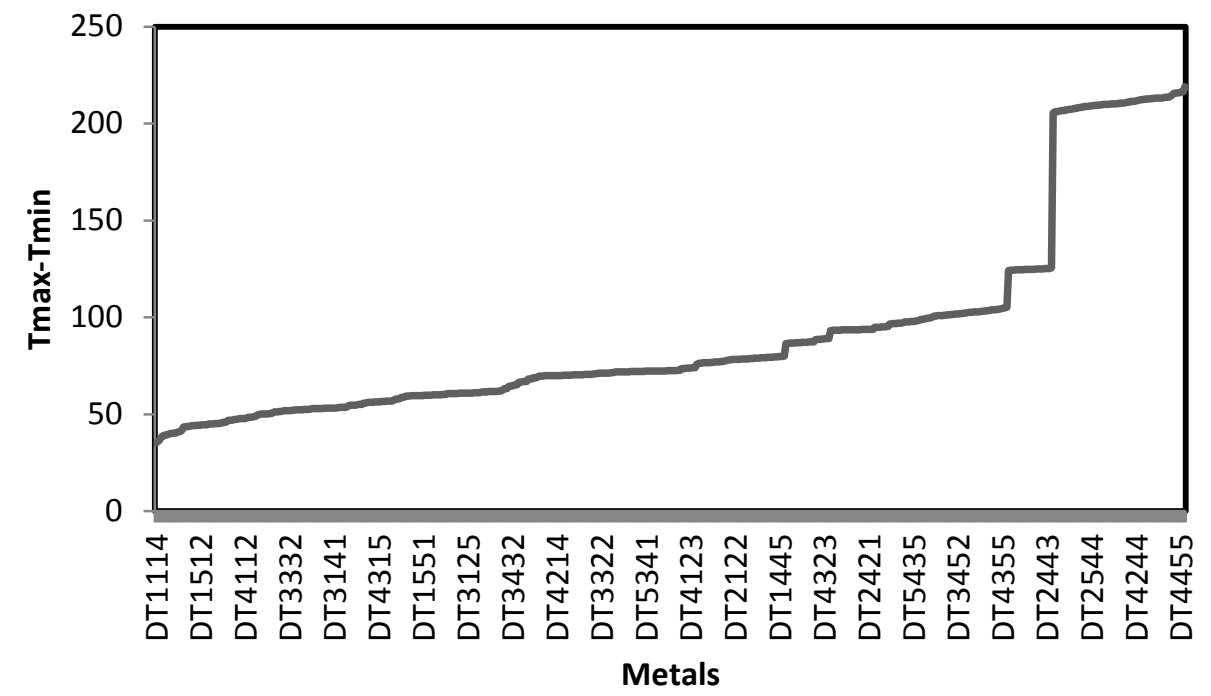

Figure 3. Temperature differences on cooking surfaces of multi-metal plates.

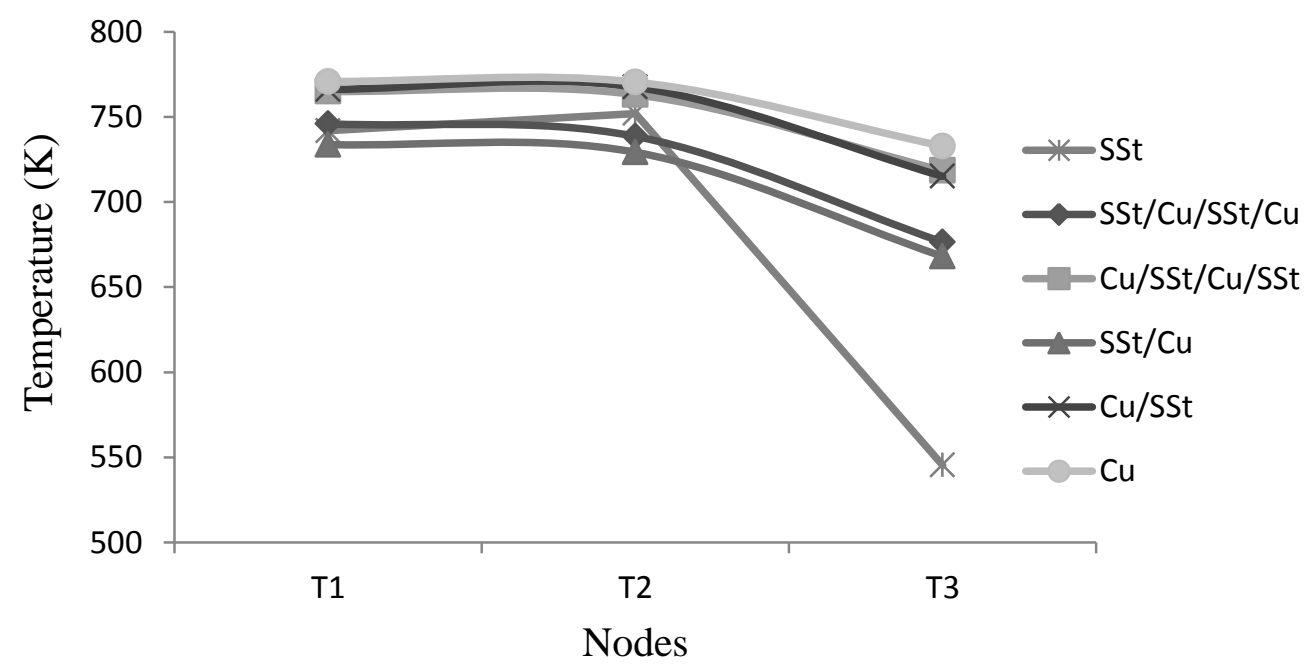

Figure 4. Temperature distribution on cooking surfaces of single and multi-metal plates consisting of copper and stainless steel. 
Cookware manufacturers usually clad non-reactive and resistant metal, namely stainless steel, exteriors around a core made out of a more conductive material, such as copper. Figure 4 compares the temperature distribution through the one to four layers consisting of copper and stainless steel. The bi-layer plate consisting of copper (7.5 $\mathrm{mm})$ and stainless steel $(2.5 \mathrm{~mm})$ provides the most uniform cooking surface. Also the figure demonstrates that the maximum temperature difference occurs with single-layer stainless steel due to its poor heat conduction. The data in Table 1 has been selected from among the 625 points (models) of Figures 2 and 3 which have higher values of the two parameters than others. According to this table, the single-layer plate of copper provides the highest mean temperature on the cooking surface. However, the bi-layer plates including $\mathrm{P}_{\mathrm{Cu} / \mathrm{CrNi}}, \mathrm{P}_{\mathrm{Cu} / \mathrm{SSt}}, \mathrm{P}_{\mathrm{Cu} / \mathrm{Al}}, \mathrm{P}_{\mathrm{Cu} / \mathrm{Ti}}$ and three-layer plates including $\mathrm{P}_{\mathrm{Cu} / \mathrm{Al} / \mathrm{Cu} \text {, }}$ $\mathrm{P}_{\mathrm{Cu} / \mathrm{Al} / \mathrm{CrNi}}$ and $\mathrm{P}_{\mathrm{Al} / \mathrm{Cu} / \mathrm{SSt}}$ provide high mean temperatures also. The lower the temperature difference (DT), the higher the uniformity will be. Based on Table 1, the $\mathrm{P}_{\mathrm{Cu} / \mathrm{CrNi}}$ bi-layer plate provides the most uniformity on the cooking surface. Thereafter, the $\mathrm{P}_{\mathrm{Cu} / \mathrm{SS}}, \mathrm{P}_{\mathrm{Cu} / \mathrm{Ti}}$, $\mathrm{P}_{\mathrm{Cu}}$ single-layer plates and the four-layer plate of $\mathrm{P}_{\mathrm{Cu} / \mathrm{Al} / \mathrm{Cu} / \mathrm{SSt}}$ have the next highest uniformity respectively.

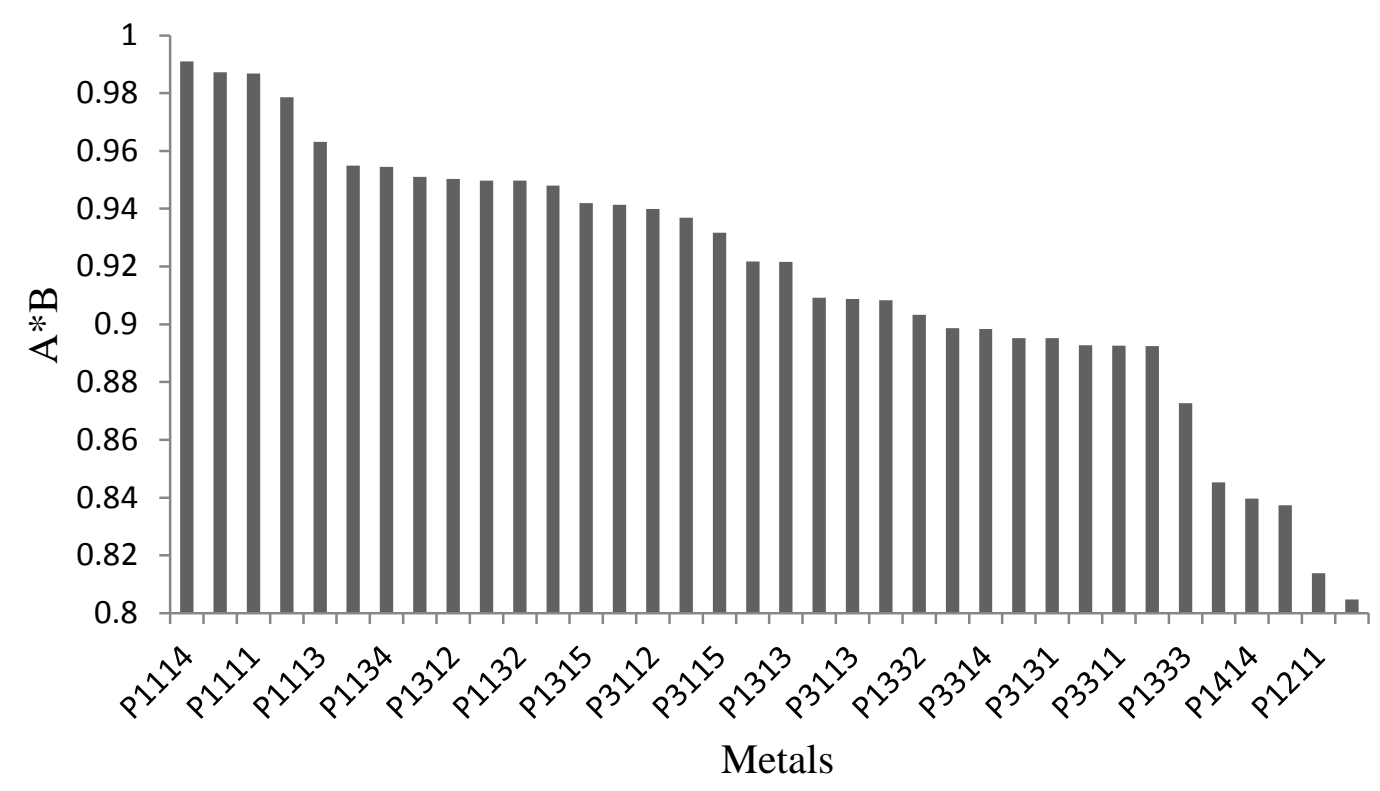

Figure 5. Normalized mean temperature and temperature differences of Table 1.

$\mathrm{A}=$ normalized mean temperature; $\mathrm{B}=$ normalized temperature difference.

Figure 5 demonstrates the normalized data of Table 1 to find the plate which provides the highest Tmean and lowest DT. According to the figure, the bi-layer cookware of $\mathrm{P}_{\mathrm{Cu} / \mathrm{CrNi}}$ has the best performance against the two parameters of mean temperature and uniformity. After this, the $\mathrm{P}_{\mathrm{Cu} / \mathrm{SSt}}$ and $\mathrm{P}_{\mathrm{Cu} / \mathrm{Ti}}$ bi-layers, $\mathrm{P}_{\mathrm{Cu}}$ single-layer, the $\mathrm{P}_{\mathrm{Cu} / \mathrm{Ti}}$ and $\mathrm{P}_{\mathrm{Cu} / \mathrm{Al}}$ two-ply and the four-layer plate of $\mathrm{P}_{\mathrm{Cu} / \mathrm{Al} / \mathrm{Cu} / \mathrm{SSt}}$ show satisfactory behavior with respect to the two parameters as cookware. These results match the research results of Ayata, Çavuşog `lu [18], who applied numerical modeling of a $\mathrm{CrNi}$ saucepan with layered bases of different alloys of aluminum and copper. They found that copper performs better than aluminum as the bottom layer. 
Table 1. Mean temperature and temperature differences on cooking surface of selected plates.

\begin{tabular}{llllll}
\hline Metals & Tmean & DT & Metals & Tmean & DT \\
\hline 1111 & 758.0082 & 37.61687 & 1331 & 754.782 & 45.38596 \\
1114 & 757.2483 & 35.19641 & 3113 & 754.6477 & 45.03116 \\
1112 & 757.2213 & 35.83858 & 3115 & 754.6413 & 40.63268 \\
1113 & 757.2164 & 40.28539 & 1334 & 754.0766 & 43.71586 \\
1115 & 756.7444 & 36.40339 & 1332 & 753.9688 & 44.59857 \\
1131 & 756.6134 & 41.24785 & 3131 & 753.9323 & 46.10216 \\
1311 & 756.3964 & 41.01728 & 3311 & 753.6231 & 45.91908 \\
1134 & 755.8908 & 39.04713 & 1333 & 753.5736 & 49.68836 \\
1132 & 755.8272 & 39.80419 & 1335 & 753.499 & 45.14755 \\
1314 & 755.7871 & 38.72077 & 3134 & 753.4489 & 44.37377 \\
1312 & 755.7236 & 39.46157 & 3132 & 753.329 & 45.26532 \\
1133 & 755.6343 & 44.66116 & 3314 & 753.2758 & 44.05708 \\
3111 & 755.586 & 41.69657 & 3312 & 753.1544 & 44.93259 \\
1313 & 755.4528 & 44.31465 & 1214 & 749.0477 & 45.14755 \\
1135 & 755.3544 & 40.3582 & 1414 & 748.596 & 45.26532 \\
1315 & 755.252 & 40.01501 & 1514 & 748.4439 & 45.38596 \\
3114 & 755.1855 & 38.72077 & 1211 & 746.5662 & 45.91908 \\
3112 & 755.1099 & 40.08198 & 1411 & 745.8267 & 46.10216 \\
\hline
\end{tabular}

\section{CONCLUSIONS}

Two-dimensional finite element analysis of heat transfer in multi-layer plates when heating non-uniformly was investigated at steady-state conditions. The analysis was extended to include varying numbers of layers, thicknesses of layers and materials. We applied $\mathrm{Cu}, \mathrm{Al}, \mathrm{SSt}, \mathrm{CrNi}$ and $\mathrm{Ti}$ in one to four layers in order to find the two parameters of mean temperature and uniformity on the cooking surfaces of the plates. In this part of the study, 625 models were analyzed. The results clearly showed that, when the first layer which is exposed to heat is a conductive metal like copper or aluminum, the cookware demonstrates a higher mean temperature and greater uniformity on the cooking surface. Through investigation of the 625 models with one to four layers, we found that bi-layer plates of $\mathrm{P}_{\mathrm{Cu} / \mathrm{CrNi}}$ and $\mathrm{P}_{\mathrm{Cu} / \mathrm{SSt}}$ provide the best performance as cookware. All-clad copper and aluminum plates have lower temperature gradients than single- layer aluminum and all-clad aluminum core plates. Also, single-layer stainless steel is unsuitable to use as cookware due to its poor heat conduction.

\section{ACKNOWLEDGEMENTS}

The authors would like to thank the Faculty of Mechanical Engineering of Islamic Azad University Bueenzahra Branch for financial support . 


\section{REFERENCES}

[1] Rhee K, Han W, Park H, Kim S. Fabrication of aluminum/copper clad composite using hot hydrostatic extrusion process and its material characteristics. Materials Science and Engineering: A. 2004;384:70-6.

[2] Lee J, Bae D, Chung W, Kim K, Lee J, Cho Y. Effects of annealing on the mechanical and interface properties of stainless steel/aluminum/copper cladmetal sheets. Journal of Materials Processing Technology. 2007;187:546-9.

[3] Omer AM. Built environment: Relating the benefits of renewable energy technologies. International Journal of Automotive and Mechanical Engineering. 2012;5:561-75.

[4] Sarkar A, Erdogdu F, Singh P. Measurement of spatial variations of heat transfer coefficient on flat surfaces for food processing applications. Conference of food engineering American Institute of Chemical Engineers, New York, USA2001.

[5] Pan Z. Temperature distribution and heat transfer coefficient of a clamshell grill. Conference of food engineering American Institute of Chemical Engineers, New York, USA2001.

[6] Sedighi M, Dardashti BN. Heat Transfer Modeling in Multi-Layer Cookware Using Finite Element Method. International Journal of Science and Engineering Investigations. 2012;1.

[7] Kohli S, Srinivasan J, Mukunda H. Heat transfer to a horizontal disc using a buoyancy-induced jet. International journal of heat and mass transfer. 1993;36:4049-66.

[8] Ashman P, Junus R, Stubington J, Sergeant G. The effects of load height on the emissions from a natural gas-fired domestic cooktop burner. Combustion science and technology. 1994;103:283-98.

[9] Sabilov C, Farkas B, Keener K. Finite element analysis of heat transfer in Cookware. IFT Conference, Poster session2001.

[10] Jugjai S, Rungsimuntuchart N. High efficiency heat-recirculating domestic gas burners. Experimental thermal and fluid science. 2002;26:581-92.

[11] Lucky RA, Hossain I. Efficiency study of Bangladeshi cookstoves with an emphasis on gas cookstoves. Energy. 2001;26:221-37.

[12] Karzar Jeddi M, Kazemzadeh Hannani S, Farhanieh B. Study of MixedConvection Heat Transfer from an Impinging Jet to a Solid Wall Using a FiniteElement Method-Application to Cooktop Modeling. Numerical Heat Transfer, Part B: Fundamentals. 2004;46:387-97.

[13] Ayata T. Temperature distributions in a copper and aluminium layered base of a CrNi-steel saucepan. Applied energy. 2005;80:341-7.

[14] Sedighi M, Dardashti BN. A Review of Thermal and Mechanical Analysis in Single and bi-layer Plate. Materials Physics and Mechanics. 2012;14:37-46.

[15] Bergman TL, Incropera FP. Introduction to heat transfer: John Wiley \& Sons; 2011.

[16] Richardson P. Thermal technologies in food processing: Taylor \& Francis; 2001.

[17] Logan D. A first course in the finite element method: Cengage Learning; 2011.

[18] Ayata T, Çavuşog lu A, Arcaklıg ${ }^{`} l u$ E. Predictions of temperature distributions on layered metal plates using artificial neural networks. Energy conversion and management. 2006;47:2361-70. 


\section{NOMENCLATURE}

$\begin{array}{llll}D T & \mathrm{~T}_{\max }-\mathrm{T}_{\min }(\mathrm{K}) & C u & \text { copper } \\ \{f\} & \text { force matrix } & A l & \text { aluminum } \\ \{g\} & \text { gradient matrix } & C r N i & \text { chromium nickel } \\ {[K]} & \text { element stiffness matrix } & T i & \text { titanium } \\ N & \text { shape function } & S S t & \text { stainless steel } \\ Q & \text { constant heat source } & & \\ q & \text { heat flux } & & \\ \text { Tmean } & \text { average temperature }(\mathrm{k}) & & \\ & & \\ \text { Subscripts } & & \\ c & \text { conduction } & \\ h & \text { convection } & & \\ P & \text { plate } & & \end{array}$

